\title{
A REPRESENTAÇÃO POR MAPAS MENTAIS PARA TRABALHAR A VIOLÊNCIA NAS AULAS DE GEOGRAFIA
}

\author{
Henrique Sabino da Silva Pereira ${ }^{1}$ Josandra Araújo Barreto de Melo $^{2}$
}

\begin{abstract}
1 Licenciado em Geografia pela Universidade Estadual da Paraíba (UEPB). E-mail: henriquesabinop@gmail.com; ORCID: https://orcid.org/0000-0002-8968-6218.

2 Professora Doutora na Universidade Estadual da Paraíba (UEPB). E-mail: ajosandra@yahoo.com.br; ORCID: https://orcid.org/0000-0002-9826-587X.
\end{abstract}

Artigo recebido em 26/04/2021 e aceito em 18/06/2021

\begin{abstract}
RESUMO: A partir da compreensão da importância dos mapas mentais para o ensino-aprendizagem espacial, foi desenvolvida pesquisa durante as aulas de Geografia, com discentes do $6^{\circ}$ ano do Ensino Fundamental de uma escola pública localizada na Zona Leste de Campina Grande, PB. Tomando como referência o método fenomenológico e as técnicas da pesquisa colaborativa, o projeto foi realizado através da criação de situações de ensino-aprendizagem pautadas na representação, estudo e compreensão do lugar de vivência, buscando resgatar, por meio dos mapas mentais, as percepções descritas pelos discentes nas representações espaciais. Foi possível verificar que, apesar da Zona Leste ser conhecida como violenta, situação agravada pela forma como os meios de comunicação social noticiam os fatos ocorridos nessa região da cidade, os discentes não vivenciam esse fenômeno socioespacial da forma como é apresentada pela imprensa, pois apenas a minoria identificou a pichação como forma de violência na comunidade, apesar de em suas casas serem colocados dispositivos de segurança, como grades e cercas elétricas. Por fim, a pesquisa disponibiliza informações sobre o trabalho com mapas mentais e suas contribuições no ensino-aprendizagem, aludindo à operacionalização sobre o espaço geográfico, a partir da representação/leitura espacial e à construção de valores cidadãos, competências que sintetizam os objetivos do ensino de Geografia na escola básica.
\end{abstract}

Palavras-Chave: lugar; mapas mentais; violência; Ensino de Geografia.

\section{REPRESENTATION BY MENTAL MAPS TO WORK FOR VIOLENCE IN GEOGRAPHY CLASSES}

\begin{abstract}
Through the comprehension of the importance of mental maps for the spatial teaching-learning, a collaborative research was developed during Geography classes with students of $6^{\text {th }}$ Grade of basic education of a public school in eastern zone of Campina Grande-PB. Taking as reference the phenomenological method and the techniques of collaborative research, the project was made through creation of teaching-learning situations based on representation, study and representation of living place, aiming to retrieve by mental maps, the perceptions described by the students in the special
\end{abstract}


representations. It was possible to verify that despite the eastern Zone being known as violent, situation aggravated by the way that media reports the events at this city region, the students do not experience this socio spatial phenom in the way it is presented by the press, since the minority has identified spray painting as form of violence in the community, although their houses having security devices as iron grids and electric fences. Lastly, the research provides pieces of information about the work with mental maps and its contribution in the teaching-learning process, alluding to operationalization about the geographic space from the representation/reading and the construction of citizen values, skills that synthetize the objectives of the geography teaching at basic education.

Keywords: place; mental maps; violence; Geography Teaching.

\section{REPRESENTACIÓ MEDIANTE MAPAS MENTALES PARA TRABAJAR POR LA VIOLENCIA EN LAS CLASES DE GEOGRAFIA}

\section{RESUMEN}

A partir de lo entendimiento de la importancia de los mapas mentales para la enseñanza-aprendizaje espacial, fue elaborada una investigación colaborativa en las clases de Geografía con alumnos del $6^{\circ}$ grado de Enseñanza Primaria de una escuela pública en la Zona Leste de Campina Grande-PB. Tomando como referencia el método fenomenológico e las técnicas de la investigación colaborativa, el proyecto se realizó a través de la creación de situaciones de enseñanza-aprendizaje basadas en la representación, estudio y comprensión del lugar donde se vive, usando los mapas mentales con el intento de rescatar las percepciones descritas por los alumnos en las representaciones espaciales. Se pudo detectar, aunque la Zona Leste es conocida por su violencia (situación agravada por la forma en que los medios informan de los hechos ocurridos en esta región de la ciudad), los estudiantes no experimentan este fenómeno socioespacial tal y como lo presenta la prensa, la minoría identificó el graffito como forma de violencia en la comunidad, a pesar de que en sus hogares se colocan dispositivos de seguridad, como rejas de hierro y vallas eléctricas. Finalmente, la investigación aporta información sobre el trabajo con mapas mentales y sus contribuciones a la enseñanza-aprendizaje, aludiendo a la operacionalización sobre el espacio geográfico, a partir de la representación/lectura espacial y a la construcción de valores ciudadanos, competencias que sintetizan los objetivos de la enseñanza de la Geografía en la escuela primaria.

Palabras-clave: lugar; mapas mentales; violência; Enseñanza de Geografía.

\section{INTRODUÇÃO}

O desenvolvimento desta pesquisa foi motivado pela necessidade de valorização de métodos de ensino-aprendizagem de Geografia que buscassem aproximar o conteúdo curricular com a realidade discente. Para tanto, colocamos em prática estratégias didáticopedagógicas que despertassem maior interesse pela disciplina, articulando-a com a realidade e, para isso, elegemos a ferramenta mapas mentais para estimular a leitura espacial pelos alunos, tomando-se como eixo condutor o fenômeno socioespacial da violência urbana.

Morais e Melo (2015) afirmam que entre os desafios do trabalho docente está a necessidade de estimular o conhecimento geográfico de maneira significativa para os 
estudantes, minimizando as suas dificuldades em relação à compreensão de muitos conteúdos da Geografia, que se acentuam, principalmente, por não se atentarem à relação dialética estabelecida entre as categorias que compõem a Geografia. Diante desse panorama, Penha e Melo (2019) asseguram que propostas de mediações pedagógicas no ensino de Geografia que sistematizam os conteúdos relacionando as vivências dos discentes com o lugar, tornam o ensino mais significativo.

Por outro lado, os mapas mentais se apresentam como uma das alterativas para promover o ensino e aprendizagem. Richter (2011) reforça que o uso dessa ferramenta no ensino de Geografia desenvolve o interesse em estabelecer conexões com as representações cartográficas, tornando os estudantes capazes de desenvolver atenção às questões espaciais. Tuan (1983), por seu turno, afirma que a representação através de mapas tem a capacidade de conceituar as relações espaciais, a forma em que os espaços estão dispostos e como se relacionam entre si e por meio das relações com os indivíduos. E, ainda de acordo com o autor, quando o discente desenvolve a alfabetização cartográfica ainda na infância, facilita a orientação em um lugar desconhecido, aperfeiçoando sua habilidade espacial. Dessa forma, fica evidente o papel da cartografia na construção de conhecimentos referentes à localização, tomando-se por referência as experiências dos primeiros anos do ensino básico.

Esse mesmo entendimento é compartilhado por vários autores que discutem a cartografia escolar, indicando que apenas o aluno mapeador se tornará um bom leitor crítico de mapas, é o caso de Oliveira (1978), Martinelli (1998; 2008), Almeida e Passini (1999) e Simielli (1999), dentre outros. Todos eles concordam com essa perspectiva e complementam que, inicialmente, deve-se prover o ensino de mapas, com a construção de legenda, noções de lateralidade, escala e orientação; para então fazer uso do ensino pelo mapa, quando se desenvolve a capacidade de leitura da informação.

Os mapas mentais são um recurso da cartografia social que possibilitam o estudo e compreensão da categoria geográfica lugar. Utilizando-se dos preceitos da fenomenologia, a corrente humanista da Geografia aborda a categoria lugar como um espaço onde os seres humanos vivenciam a experiência. Conforme Holzer (1999, p. 70), "Um centro gerador de significados geográficos, que está em relação dialética com o constructo abstrato que denominamos "espaço"”.

Partindo dessa concepção teórica e articulando com as possibilidades trazidas pela representação através dos mapas mentais, verifica-se que existe toda uma carga de 
significados na leitura espacial desenvolvida pelos estudantes. Estes são capazes de perceber e representar a realidade espacial, com toda a sua carga de simbolismos. Tudo isso torna possível a promoção de mudanças paradigmáticas no ensino da Geografia, pois as aulas terão mais significado, a partir da articulação com a realidade, podendo gerar discussões sobre as características do lugar e a sua gestão, configurando uma abordagem de cunho crítico e social. Portanto, como Pereira, Rosales e Melo (2018) apresentam, essa linguagem cartográfica possibilita ao professor de Geografia trabalhar problemáticas socioambientais, econômicas, representando também a totalidade de ações dos sujeitos no espaço e as diferentes maneiras de como o espaço é vivenciado pelos indivíduos.

A cartografia não convencional oferece subsídio ao ensino de Geografia através de ilustrações e, até mesmo desenhos, tendo em vista que "é sabido que a mente humana tem melhores condições de aprender o contorno de uma figura que a sua descrição escrita. Aprende-se a desenhar antes mesmo de aprender a ler" (ALEGRE, 1983, p. 24). Parte-se, assim, da representação dos elementos espaciais percebidos, sem maiores preocupações técnicas, para uma discussão mais aprofundada, que faça uso dos elementos cartográficos, mas que tenham um cunho social e de compreensão da realidade representada.

Com relação à questão da violência urbana, já mencionada enquanto enfoque nesta pesquisa, Rodrigues (2002) analisa essa problemática sob o ponto de vista do crescimento populacional nas cidades, que não conseguem suprir as necessidades dos seus habitantes, privando-os do direito à cidade. Tudo isso resulta em atitudes indesejadas das pessoas que convivem constantemente com a insegurança: "Morosidade, mau humor, hostilidades dissimuladas ou ostensivas, desordens psicológicas, violência. Crimes são sintomas diversos de uma síndrome e se encontram num mesmo lugar social, que é o medo" (SANTOS, 2002, p. 126). O medo faz companhia aos indivíduos em seu percurso rotineiro e é também fator determinante para o esvaziamento dos espaços públicos, principalmente os de lazer.

Tendo em vista notícias veiculadas pela imprensa acerca da violência na Zona Leste da cidade de Campina Grande, PB, a exemplo da que é apresentada na Figura 4 do presente texto, esta equipe de pesquisa se debruçou para desenvolver práticas em sala de aula que viabilizassem a compreensão de como os alunos do $6^{\circ}$ ano do ensino fundamental percebiam as notícias veiculadas pela mídia no cotidiano na cidade e o seu reflexo no espaço escolar, através da propagação da violência e do medo. Para compreender como os alunos percebem o fenômeno da violência em seu cotidiano e no seu espaço de vivência, a pesquisa foi 
desenvolvida através de práticas colaborativas nas aulas de Geografia da turma, fazendo uso da ferramenta mapas mentais, com o objetivo de refletir sobre os problemas presentes no cotidiano dos alunos, fazendo com que eles ampliassem o conhecimento sobre os fenômenos socioespaciais e ambientais locais e começassem a desconstruir aspectos negativos ou estereótipos disseminados sobre o seu lugar.

\section{MATERIAL E MÉTODOS}

\section{Espaço de desenvolvimento da pesquisa}

A pesquisa foi realizada na turma de $6^{\circ}$ ano $\mathrm{C}$, turno vespertino, da Escola Cidadã Integral Estadual de Ensino Fundamental e Médio Assis Chateaubriand, localizada na rua Alice Gaudêncio, S/N, Santo Antônio, bairro pertencente à Zona Leste da cidade de Campina Grande, PB.

De acordo com a pesquisa de Barros (2020), publicada em editorial da Revista Veja, analisando o relatório publicado pela da Fundação City Mayors, Centro de Estudos dedicados aos temas urbanos, Campina Grande encontra-se entre as cidades mais perigosas do Brasil, ocupando o $9^{\circ}$ lugar em homicídios, com o índice de 46 por 100 mil habitantes e $25^{\circ}$ no ranking geral da violência no Brasil. Trata-se da única Cidade do país que está nesse ranking, mesmo não sendo uma capital.

No caso da Zona Leste da cidade, o conhecimento empírico acumulado acerca desse espaço da cidade faz esta equipe de pesquisa compreender que essa violência é fruto de problemas socioeconômicos e do tráfico de drogas, o que reflete no cotidiano escolar, que necessita ser inspecionado cotidianamente pela administração escolar; a escola precisa de muros altos e de manutenção de alerta por tempo integral. Afora isso, a violência também se manifesta no espaço escolar de outras formas como o bullying e a depredação do patrimônio público, através de danos materiais e pichações, embora tenha acabado de passar por uma reforma. Na figura 1 é possível visualizar a depredação sob a forma de pichação, onde é possível identificar a sigla ZL - que significa Zona Leste, demonstrando uma forte identidade com o lugar de vivência. Por se localizar em uma área da cidade considerada violenta, são tomadas medidas de prevenção às ações externas que podem atingir o ambiente escolar, como 
exemplo pode-se observar, também na figura 1, que o muro da escola foi elevado e implantado o sistema de cerca elétrica.

Figura 1: Pichação no interior da Escola e Aumento do muro e instalação de cerca elétrica na Escola Assis Chateaubriand.

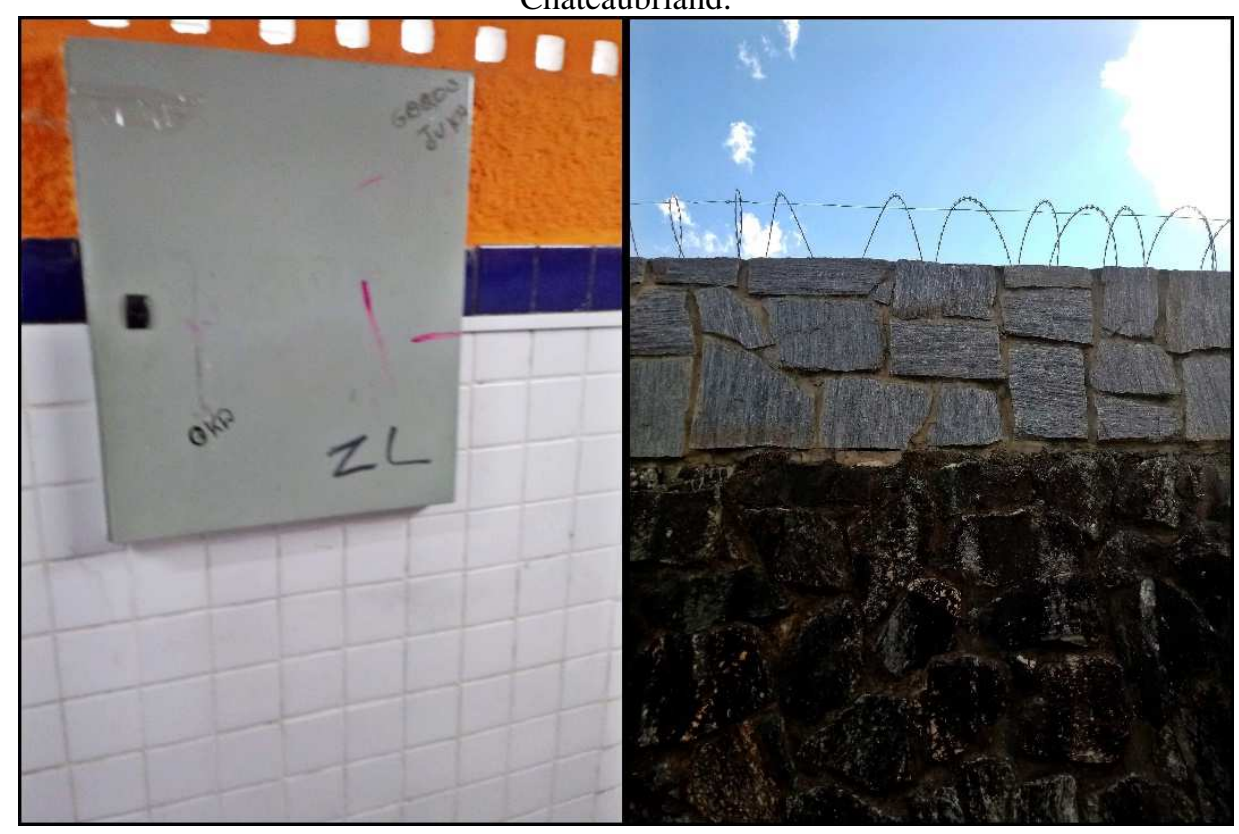

Fonte: Arquivo de imagens dos autores (2019).

Através da imagem é possível verificar que, sobre a estrutura do muro mais antigo, foi construída uma nova e colocado cerca uma elétrica visando impedir o acesso de indivíduos para o tráfico e consumo de drogas no interior da escola.

\section{Método e técnicas implementadas na pesquisa}

A pesquisa foi desenvolvida no primeiro semestre do ano letivo de 2019, inicialmente com a participação dos 29 discentes matriculados na turma do $6^{\circ}$ ano "C", entretanto, nas duas últimas etapas da coleta de dados, participaram os 9 discentes que apresentaram maior interesse em contribuir com a pesquisa.

Constitui uma pesquisa qualitativa, modalidade pesquisa colaborativa, pela sua adequação à necessidade de obtenção dos resultados a partir da percepção dos alunos, possibilitando à equipe a verificação dos fenômenos e a maneira como se manifestam no convívio diário (GODOY, 1995, p. 6). A análise e descrição através das técnicas da pesquisa 
possibilitou a coleta de dados fiéis às experiências vividas e relatadas pelos discentes participantes.

Quanto às técnicas da pesquisa colaborativa, elas proporcionam, segundo Horikawa (2008), a aproximação do pesquisador colaborativo com o local do estudo que, através do diálogo entre os participantes, intervenções, coleta de informações, permite ao pesquisador maior compreensão para uma melhor interpretação do fenômeno, alcançando os objetivos propostos.

A análise de dados foi fundamentada no método fenomenológico que, de acordo com Holzer (1997), descreve minuciosamente o mundo vivido e suas interações humanas, sem descartar a sua essência. Dessa forma, buscou-se interpretar a percepção individual dos alunos acerca da comunidade e dos seus problemas, representados pelos mapas mentais e relatados através de produção textual específica e das opiniões emitidas nos grupos focais.

Ainda sobre a fenomenologia, correlaciona-se o recorte feito por Coltro (2000, p. 39), quando diz que: "A fenomenologia exalta a interpretação do mundo que surge intencionalmente à consciência, enfatizando a experiência pura do sujeito [...]". Também de acordo com o autor, possibilita ao pesquisador o contato direto com o fenômeno, envolvendoo com as ações presentes no cenário de estudo, facilitando assim a interpretação dos instrumentos de coleta de dados.

Sobre os grupos focais, são uma técnica da pesquisa qualitativa "uma estratégia de campo que combina, ao mesmo tempo, a participação ativa com os sujeitos, a observação intensiva em ambientes naturais, entrevistas abertas informais e análise documental" (MOREIRA, 2002, p. 52).

O primeiro contato com a turma participante foi por meio de uma observação durante a aula de Geografia. Na ocasião, foi realizada a apresentação prévia da equipe e de como seria o desenvolvimento do projeto. Na semana seguinte, houve a primeira participação da equipe através da aplicação de um questionário com o intuito de obter informações sobre a percepção dos discentes sobre a violência no lugar, no percurso casa-escola e no interior do ambiente escolar. O questionário foi constituído por questões objetivas e subjetivas, que foram interpretadas empiricamente, procurando identificar a percepção dos discentes sobre cada questão abordada.

$\mathrm{Na}$ semana seguinte, foi abordada teoricamente a categoria geográfica lugar, na perspectiva da Geografia Humanística. Foi trabalhado o conceito, realizadas exemplificações 
e mostradas ilustrações através do recurso data show. Além disso, foi solicitado que, individualmente, os discentes elaborassem um desenho que retratasse o seu lugar, como uma forma de iniciá-los na representação espacial. Na intervenção subsequente, deu-se continuidade à abordagem sobre o lugar, com enfoque na Zona Leste. Como recursos didáticos foram utilizados um mapa das zonas da cidade e um mapa dos bairros da Zona Leste, além de ilustrações de lugares bastante conhecidos na cidade.

A categoria geográfica trabalhada a seguir foi a de paisagem, ocasião em que foi abordado o seu conceito e modalidades - paisagem natural e paisagem cultural. Foram utilizadas imagens do Brasil, de outros países, de Campina Grande na íntegra e da Zona Leste, para que os alunos identificassem que tipo de paisagem cada ilustração representava. Foi utilizado também a música como recurso didático, tendo sido reproduzidas as músicas "Súplica cearense", interpretada pela banda "O Rappa", e "Janela da Favela", da banda "Ponto de Equilíbrio". Cada aluno recebeu as letras das músicas impressas, cada música foi reproduzida uma vez. Em seguida, houve um debate para que os discentes compreendessem a relação da letra com a categoria em análise trabalhada.

A equipe percebeu que a turma ainda estava com dificuldade de entender os objetivos do projeto e, na intervenção seguinte, realizou uma aula expositiva sobre os conceitos de lugar, não-lugar e lugar social e, nos minutos finais, foi cobrado aos discentes uma produção textual para que eles descrevessem o seu lugar.

Para tratar a temática da violência, foi abordada a violência urbana e suas nuances, apresentando as formas como esse fenômeno social pode alcançar o lugar de vivência e a escola. Durante essa intervenção, houve um debate sobre o tema, seguido da distribuição da letra da música "O Calibre", da banda "Paralamas do Sucesso", concluindo com uma discussão sobre ela.

$\mathrm{Na}$ sequência, foram apresentados aos discentes a cartografia e os mapas mentais, iniciando uma alfabetização cartográfica e o significado da representação através da ferramenta. $\mathrm{Na}$ aula seguinte, foi realizada a primeira oficina de mapas mentais, onde os discentes representaram o seu lugar, com as suas visões acerca da violência enquanto fenômeno socioespacial.

$\mathrm{Na}$ semana posterior, foi continuada a oficina de produção de mapas mentais, sendo selecionados 10 discentes que mais se mostraram empenhados em contribuir com a pesquisa. Dos selecionados, nove estavam presentes em sala e participaram do grupo focal, os discentes 
foram divididos em dois grupos, um com cinco componentes e outro com quatro, para responderem questões subjetivas relacionadas ao seu lugar e à violência nele presente. $\mathrm{O}$ questionário foi composto pelas seguintes questões:

1) Quais os principais locais que você passa até chegar na escola?

2) Alguma dificuldade do caminho de casa para escola já te impediu de chegar na escola?

3) O percurso de casa para escola é perigoso? Por quê?

4) Você já sofreu com violência no lugar em que você mora?

A última atividade realizada foi a segunda oficina de mapas mentais, com os mesmos discentes que participaram do grupo focal. Nesse último momento representaram em seus mapas a sua percepção sobre os aspectos socioespaciais, com ênfase ao fenômeno da violência.

Os mapas mentais com maior quantidade de detalhes estão apresentados nos resultados desta pesquisa. Será mantido o anonimato dos discentes, utilizando-se algarismos arábicos em lugar dos seus nomes.

\section{RESULTADOS E DISCUSSÕES}

No caso presente, através da compreensão da categoria lugar, os discentes puderam representar o seu lugar, ressaltando a violência percebida no cotidiano, contribuindo para a ampliação do conhecimento, em consonância com o entendimento de Ferreira (2014), quando afirma que os mapas mentais são um recurso importante, pois proporcionam aos alunos a utilização dos seus conhecimentos cotidianos para entender as categorias geográficas, além de aperfeiçoar o conhecimento sobre o local em que vivem.

No enfoque sobre a violência enquanto fenômeno socioespacial, foi aplicado um questionário buscando coletar informações dos discentes sobre as principais formas como este se manifesta em seu lugar e no ambiente escolar. Responderam ao questionário vinte e um discentes presentes na data de sua aplicação, foi esclarecido que a identificação na atividade seria opcional, acredita-se que, assim, eles apresentariam maior desenvoltura para responder as questões.

Nas respostas aos questionários, os discentes enumeraram o racismo, o preconceito e o bullying como tipos de violência presentes no cotidiano, conduzindo a equipe a sentir a 
necessidade de trabalhar com a turma a questão da violência psicológica, dialogando sobre as principais formas como ela se manifesta no dia a dia. Com esse intuito, foi apresentada à turma uma matéria de um programa de TV sobre bullying e um vídeo para debater o preconceito, com enfoque no racismo.

Dos 21 discentes que responderam os questionários, 13 não consideraram a escola um lugar violento, descrevendo-a como um ambiente calmo, destacando a importância do serviço prestado pelos seguranças da escola. Porém, 7 discentes disseram que a escola não é segura, que a sua estrutura sofre com as depredações, além disso, ressaltaram a violência existente entre os discentes, como o bullying e o preconceito, e relataram também a presença de "maloqueiros", que não são discentes da instituição, mas ficam nos arredores da área externa da escola, na maioria das vezes, interagindo com alguns discentes. Um dos estudantes não respondeu à questão.

A partir das respostas dessa questão, foi possível identificar que, além de sofrerem com a violência urbana, os discentes também enfrentam algumas formas de violência psicológica no ambiente escolar, o que é o oposto do que se espera, já que "a escola é fundamental para o pleno desenvolvimento do indivíduo, devendo ser um dos contextos sociais que estimule as habilidades intelectuais e a absorção crítica dos conhecimentos produzidos em nossa sociedade" (PEREIRA; WILLIAMS, 2010, p. 47). A escola é uma instituição que assume importante função social e corresponde a uma fase marcante na vida dos discentes, no entanto a violência escolar pode marcar negativamente os indivíduos que dela são vítimas.

Na questão seguinte, que indagou se a escola reflete a violência urbana, apenas um discente identificou que a instituição não sofre esses reflexos e não justificou a sua resposta. Os demais relataram que a violência que a escola enfrenta é visível nas depredações das portas e das janelas de vidro das salas de aula, as torneiras dos banheiros quebradas, pichações por todo o prédio, como reflexo da violência e do descumprimento de normas da instituição.

$\mathrm{Na}$ terceira questão que perguntou se os discentes se sentem seguros no ambiente escolar, 16 responderam afirmativamente, enquanto os cinco restantes caracterizaram tal ambiente como inseguro e de violência psicológica e urbana.

$\mathrm{Na}$ quarta questão, que investigou como os discentes percebem a violência no bairro em que moram, 12 discentes responderam que o bairro e as localidades próximas da escola são espaços tranquilos, não percebendo esses espaços como violentos; nove responderam que 
não se sentem seguros, sendo a insegurança um reflexo da violência presente na cidade, sobretudo enfatizada pelos noticiários, como é o caso dos assaltos, tráfico de drogas e homicídios.

$\mathrm{Na}$ quinta questão, os discentes relataram os tipos de violência mais recorrentes dentro e fora do ambiente escolar. Os atos violentos que se manifestam dentro da escola são os conflitos entre os próprios discentes, como racismo, bullying, comportamentos agressivos e palavrões; já os problemas percebidos fora da escola são as pichações, a presença de usuários de drogas, os assaltos, as brigas e os homicídios. Os discentes não mencionaram o tráfico de drogas como sendo um problema na Zona Leste, não se sabe se por não perceberem a sua existência ou por medo de relatar.

$\mathrm{Na}$ questão seis, que indagou sobre violência nas redondezas da escola, cinco discentes assinalaram que já foram vítimas de episódios violentos, e 16 nunca sofreram com o problema.

$\mathrm{Na}$ sétima questão, três alunos responderam que já sofreram com a violência no percurso de casa para a escola; 18 alunos assinalaram que nunca sofreram violência em seu percurso rotineiro. Os mesmos três alunos também assinalaram sim na questão seguinte, que questionou se essa violência no percurso os impediu de ir para escola, o restante manteve a resposta da questão anterior.

As respostas a essas questões serviram de base para a sequência da pesquisa, desde o planejamento das estratégias didático-pedagógicas, passando pela realização de oficinas de mapas mentais e chegando ao grupo focal.

Após as estratégias de sala de aula sobre o lugar, enfocando o espaço de vivência dos discentes, foi solicitado que eles realizassem uma pequena produção textual, na qual deveriam discorrer sobre o tema. A atividade teve como objetivo direcionar o olhar dos discentes para os espaços que fazem parte da sua rotina e que apresentam relação de pertencimento, construindo, assim, um olhar geográfico. Os elementos enfatizados nos lugares caracterizados pelos discentes, em sua maioria, foram: casa de familiares, espaços religiosos e mercadinhos, sendo o último presente em todos os textos, já que constitui atividade importante para economia local e que oferece condições para que os habitantes não precisem se deslocar para outros bairros ou para a área central da cidade.

A primeira oficina de mapas mentais foi realizada no segundo bimestre letivo de 2019, após a conclusão da parte conceitual realizada nas aulas do professor de Geografia. 
Cada discente produziu um mapa mental sobre o seu lugar de vivência, em consonância com a metodologia utilizada por Richter (2011). Sobre esta, o autor destaca: “[...] ao observamos um mapa mental, temos possibilidade de analisar as interpretações que os estudantes desenvolvem sobre um determinado espaço, em que contextos, fatos e objetos são selecionados e representados de acordo com o 'olhar espacial' do aluno." (p. 146). A seguir, a figura 2 apresenta alguns mapas produzidos pelos alunos na primeira oficina de produção de mapas mentais do projeto.

Figura 2: Primeira rodada de produção de Mapas Mentais: percurso casa-escola I.

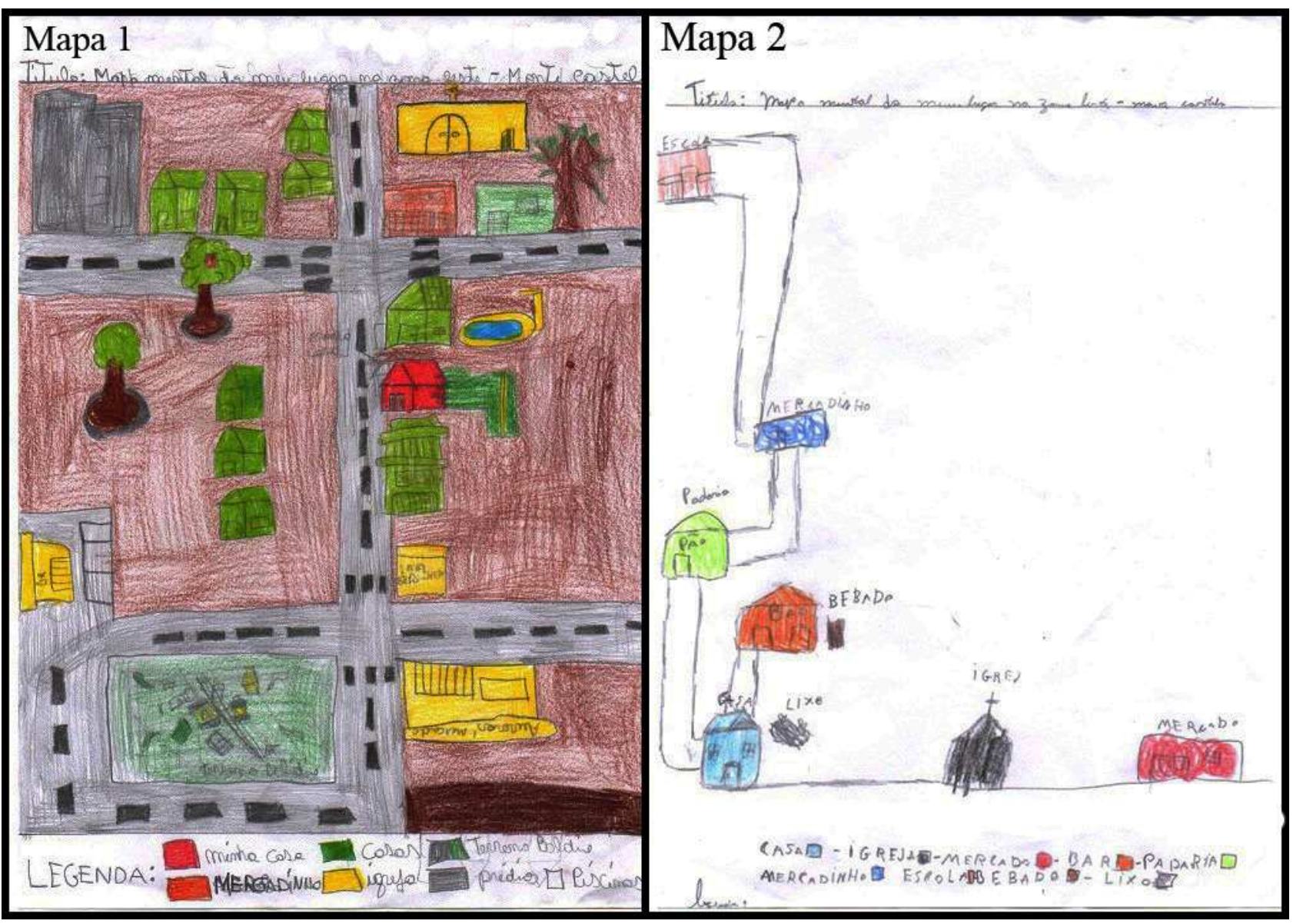




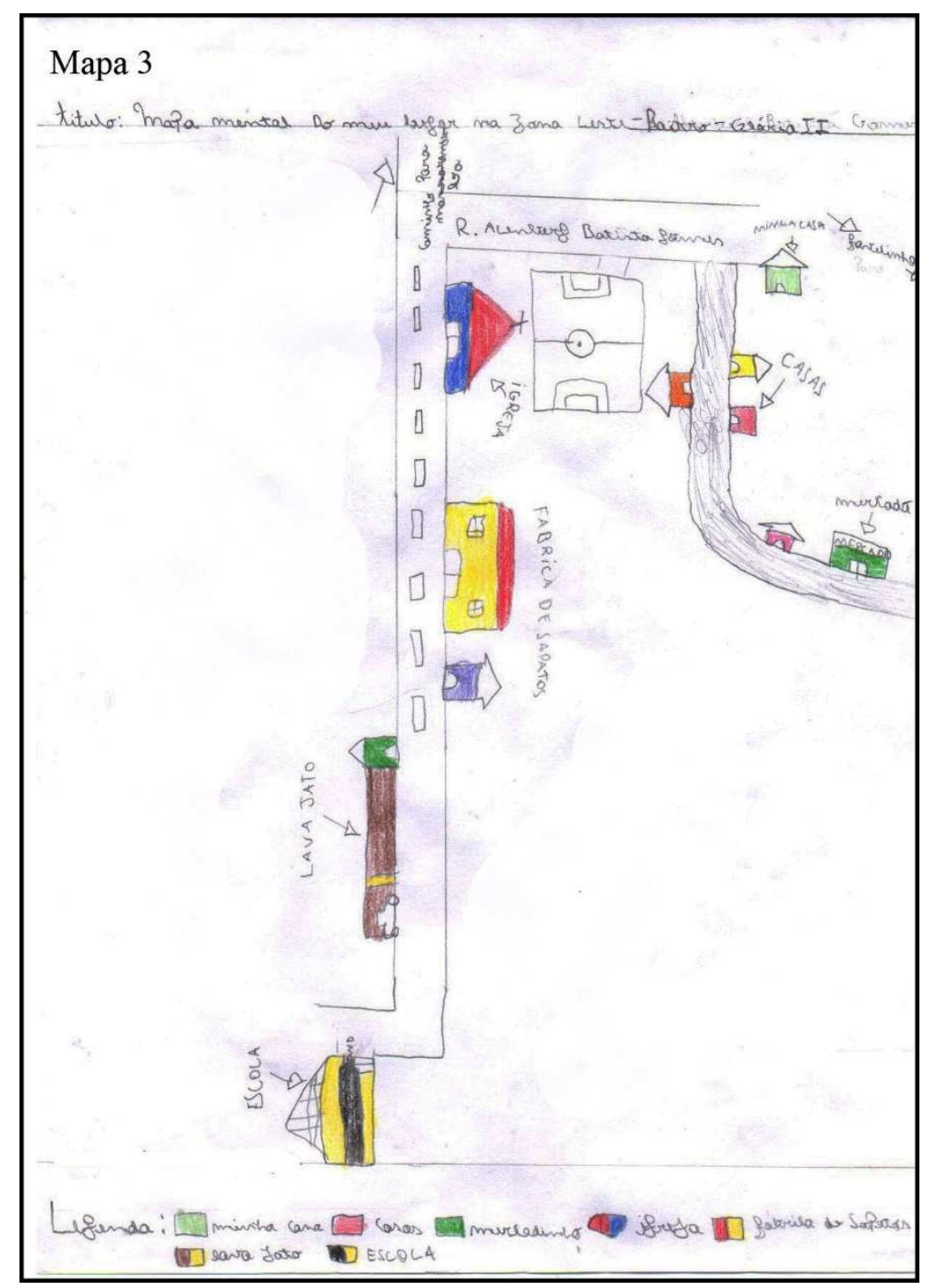

Fonte: Pesquisa junto ao Aluno 1, Aluno 2, Aluno 3 (2019).

Pelos mapas, é possível identificar elementos em comum nas três representações, são os mercadinhos e espaços religiosos. No primeiro mapa, visto da esquerda para direita, um dos pontos representados com destaque foi a disposição de resíduos sólidos num terreno baldio, na cor verde escura. O discente ilustrou alguns tipos de resíduos e a cor escolhida remete à presença de vegetação nesse espaço abandonado, destacado na figura 2. Segundo relatos do discente, moradores se desfazem dos resíduos no terreno baldio, criando uma situação propícia para o surgimento de insetos vetores à saúde humana, além disso, a vegetação alta, associada à baixa iluminação noturna, facilita os atos de violência, deixando vulneráveis os moradores do local. 
Um estudo semelhante realizado por Lopes (2018) divulgou que a representação nos mapas mentais desse tipo de problema indica o olhar crítico sobre o bairro e a falta de planejamento urbano, que ocorrem devido a omissão do poder público.

Ainda na mesma representação, o discente identificou o seu bairro, Monte Castelo, que possui vias públicas pavimentadas, representadas na cor cinza, poucas moradias verticais e também moradias horizontais, como a sua casa, na cor vermelha. Ainda ilustrados no mapa estão um mercadinho e a igreja na cor amarela, com uma cruz na frente.

Os mapas dos alunos 2 e 3 representaram o percurso com um menor nível de detalhe, se detendo mais ao traçado das ruas do trajeto, com os prédios mais marcantes. No mapa 2, o lugar retratado também é no bairro Monte Castelo, o autor representou sua casa na cor azul clara, a igreja, dois mercadinhos, o bar, a padaria e a escola. "Cada local se destaca por exercer uma atividade específica que lhe dá sentido e função na organização da estrutura urbana." (RICHTER, 2011, p. 154). Seu olhar sobre o lugar identificou a concentração de resíduos nas proximidades de sua casa, o que mostra como essa disposição inadequada está presente na rotina do local.

No último mapa, representado pelo aluno 3, o lugar de vivência é o bairro Glória II. O aluno identificou sua casa na cor verde, representou também as casas vizinhas, o mercadinho, a igreja, o lava-jato e a escola. O autor não identificou nenhum problema de violência.

É interessante mencionar que todos os mapas possuem legenda. Este fato é decorrente das práticas executadas em sala de aula antecedendo a realização das oficinas de produção de mapas.

A figura 3 apresenta as representações espaciais feitas por mais dois discentes durante a realização da primeira oficina de produção de mapas mentais. 
Figura 3: Primeira rodada de produção de Mapas Mentais: percurso casa-escola II.

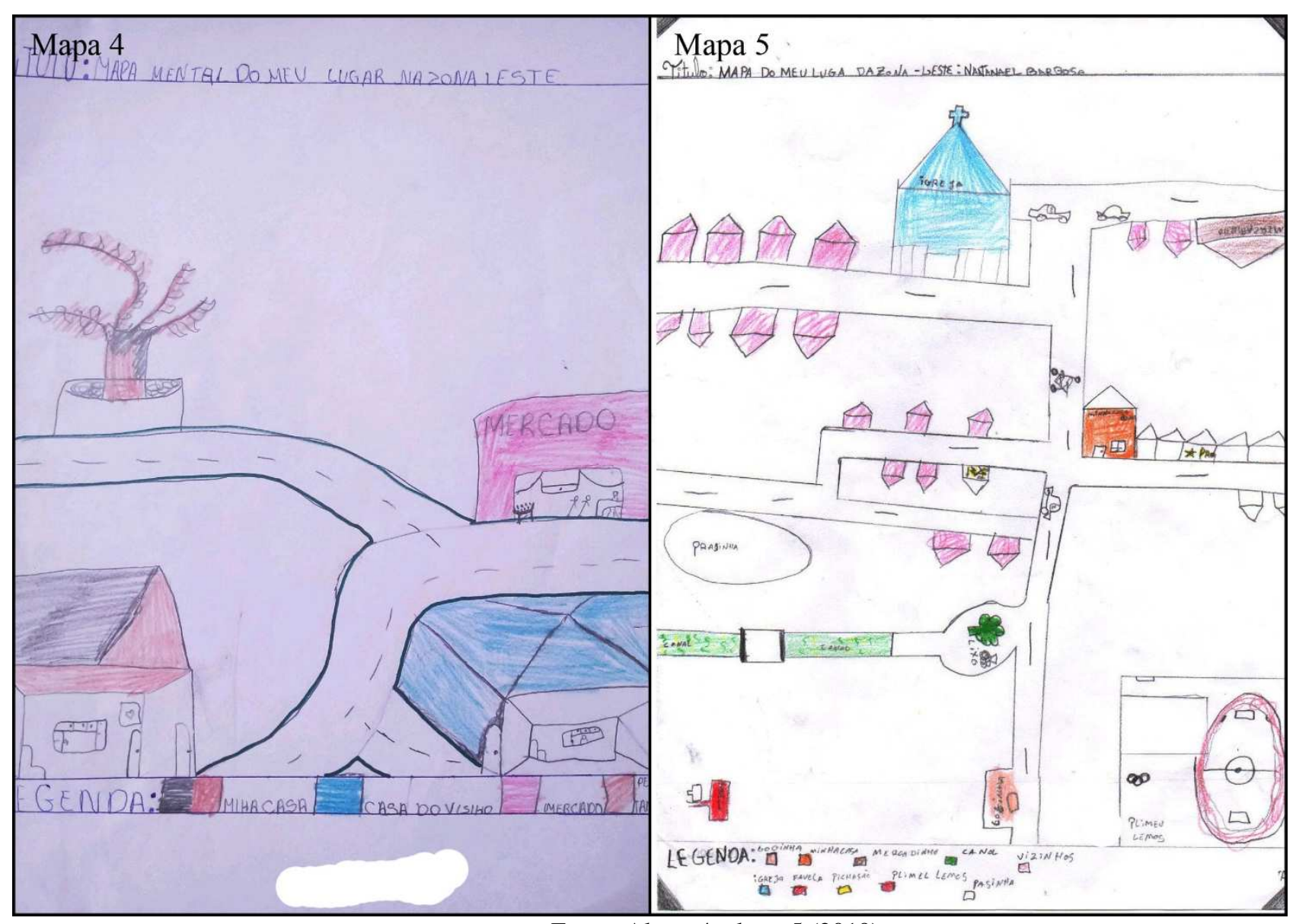

Fonte: Aluno 4, aluno 5 (2019).

No primeiro mapa, o autor fez uma representação simples, destacando a sua casa colorida em marrom e preto, a casa do vizinho, o mercado e o Pé de Tambor (grande árvore centenária localizada no bairro Nova Brasília, atualmente é um ponto de apoio para mototaxistas e contém um pequeno altar que atrai fiéis católicos, representando toda uma carga de simbolismo; também a sua sombra é utilizada para reuniões, cultos religiosos e outras sociabilidades que ocorrem no lugar).

No lugar representado no mapa 5, o autor trouxe uma quantidade maior de elementos, identificou a sua residência colorida na cor laranja, as residências dos vizinhos, o mercadinho, a igreja; em algumas residências ele destacou na cor amarela as pichações presentes. Ações dessa natureza são consideradas um tipo de violência urbana e um aspecto negativo, como aponta Sant'Anna (2009), uma vez que o vandalismo que causa danos 
materiais às propriedades, quando presente no cotidiano do jovem, pode ser visto como natural, ou seja, esse tipo de violência passa a ser naturalizada.

Ainda sobre o mapa em questão o autor teve o cuidado em representar os carros e uma motocicleta pelas vias públicas locais; do lado esquerdo do mapa está a praça (que não foi colorida). Culturalmente, as praças são espaços de interação e lazer dos moradores, assumindo grande importância na dinâmica dos bairros, apresentando valor funcional. Conforme relatam Viero e Barbosa Filho (2009), muitas praças são as principais ou até mesmo a única opção de lazer urbano, podendo apresentar atrativos como: "coretos para apresentações culturais, fontes que jorram água, bancos para descanso, quiosques com vendas de lanches, barra de ginástica, pistas de caminhadas e ciclovias, parquinhos para crianças, entre outros" (VIERO; BARBOSA FILHO, 2009, p. 3).

$\mathrm{Na}$ parte inferior do Mapa 5, o autor representou o canal que, devido à disposição incorreta de resíduos sólidos, se apresenta como um problema socioambiental no lugar, já que a concentração de resíduos nas proximidades e interior do canal, durante os períodos de chuva, dificulta o escoamento das águas pluviais, causando inundação. Em seguida, na cor vermelha, o discente representou uma favela, mais afastada das demais moradias. Esta última representação pode exemplificar a segregação residencial, que traz consigo uma série de problemas, de acordo com Sant'Anna (2009):

[...] a segregação residencial leva ao isolamento dos segmentos sociais
vulnerabilizados - quer pela economia, quer pelos novos padrões de políticas
públicas - e fragiliza os laços de interação social, desencadeando mecanismos
sociais de reprodução da pobreza e das desigualdades. (SANT'ANNA, 2009, p.
167).

Ainda sobre as favelas, especificamente sobre os seus moradores, Costa (2014) considera que cidadãos se tornam favelados pela ocupação ilegal de um espaço e, a partir de então, recebem os estereótipos de marginais, promíscuos, doentes, preguiçosos, vagabundos, perigosos, desordeiros e imorais.

Por último, na parte inferior esquerda do mapa 5, a representação da Vila Olímpica Plínio Lemos, localizada no bairro José Pinheiro. De acordo com Santos (2011), o estádio de futebol presente na Vila Olímpica, durante as décadas de 1960 e 1970 foi palco de grandes eventos esportivos em Campina Grande, mas, com passar dos anos, foi sofrendo com o processo de abandono, até que em 2008, após a revitalização, voltou a atender as necessidades de esporte e lazer da população local. Também de acordo com Santos (2011), a estrutura 
física da Vila Olímpica compreende um campo de futebol com arquibancada coberta, pista de atletismo com 400 metros, quadras de futebol e voleibol de areia, pista de skate, piscina coberta, ginásio com quadra poliesportiva, sala para a prática de artes maciais, sala de dança, playground e museu de esporte. Atualmente, parte dessa estrutura não se encontra mais em condições de uso, devido as ações de vandalismo e abandono público.

A violência também está visivelmente presente na estrutura do muro da Vila Olímpica que, em alguns pontos, foi destruída, criando entradas alternativas que facilitam o acesso e possíveis fugas de pessoas que utilizam o espaço para a venda e consumo de entorpecentes. A cobertura da arquibancada e da piscina não existem mais, inclusive a função atual da piscina é de depósito de resíduos numa expressão de abandono do local; o parque infantil também apresenta depredações e os brinquedos estão inutilizáveis, pichações estão presentes por toda a estrutura.

Após a primeira oficina de mapas, a segunda coleta de dados foi realizada com os grupos focais, onde foram reunidas informações sobre a violência no percurso rotineiro e no lugar. Os dois grupos focais responderam a primeira pergunta que versava sobre quais os principais locais que os alunos passavam no percurso casa-escola. As respostas para esta pergunta foram:

Grupo 1: O grupo respondeu que no trajeto de casa para a escola passava por um lavajato, loja de bolo, supermercados, padarias e igrejas.

Grupo 2: Os discentes relataram que no percurso casa-escola passavam por padarias, uma praça, salões de beleza, mercadinhos e casas pela vizinhança.

Essa questão representou uma oportunidade para os discentes aguçarem a percepção espacial, exercício pouco desenvolvido no cotidiano, dado que a atenção é mais voltada para o universo virtual. Nessa ocasião, foi realizada abordagem sobre a importância dos serviços disponíveis nos bairros como possibilidade de integração entre os moradores.

No que se refere à segunda questão, que indagava sobre alguma dificuldade motivada pela violência urbana que tenha sido enfrentada pelos educandos no percurso casa-escola, que tenha impedido a sua chegada no ambiente escolar, as respostas foram as seguintes:

Grupo 1: Nenhum discente relatou que deixou de ir para a escola devido a alguma adversidade no caminho, motivada pela violência. 
Grupo 2: $\quad$ Respondeu que nenhum empecilho os impediu de ir para a escola.

Essas respostas deixam claro que os problemas de tráfico de drogas e/ou outras formas de violência não interferem no deslocamento dos alunos para o espaço escolar. Talvez se a pesquisa tivesse sido realizada com alunos do turno da noite, o resultado fosse diverso. Quando indagados se o percurso de casa para escola é perigoso e, caso positivo, por que, os grupos responderam:

Grupo 1: Não considera o percurso de casa para escola perigoso, porém identifica pichações nos muros das residências. O grupo não fez menção a violência.

Grupo 2: Nenhum dos discentes relatou algum tipo de violência no lugar de vivência. O grupo também não fez menção a violência.

A resposta a esta questão demonstra que os discentes não são vítimas de violência urbana, talvez por este motivo não se considerem expostos ao perigo. Eles classificam as pichações como sendo uma forma de violência urbana, porém não como uma modalidade que lhes afete no cotidiano. Essa informação está em desacordo com a percepção que muitas pessoas de outras áreas da cidade têm sobre a Zona Leste e conduz à necessidade de estudos posteriores para identificar se os agentes produtores de violência não vitimizam as pessoas do lugar ou se a imagem da Zona Leste é estereotipada pela população de outros setores da cidade, em decorrência de eventos isolados apresentados na mídia, a exemplo do aluno da Escola Estadual de Ensino Fundamental Dr. Chateaubriand, que ameaçou de morte a gestora escolar e danificou a escola na procura pela mencionada profissional. A figura 4 apresenta um recorte de notícia que despertou a atenção da população campinense para a violência no ambiente escolar. 
Figura 4: Notícia publicada na imprensa acerca da violência em escola da Zona Leste de Campina Grande, localizada no bairro de José Pinheiro.

\section{Aluno é apreendido suspeito de ameaçar matar diretora de escola no José Pinheiro, em CG}

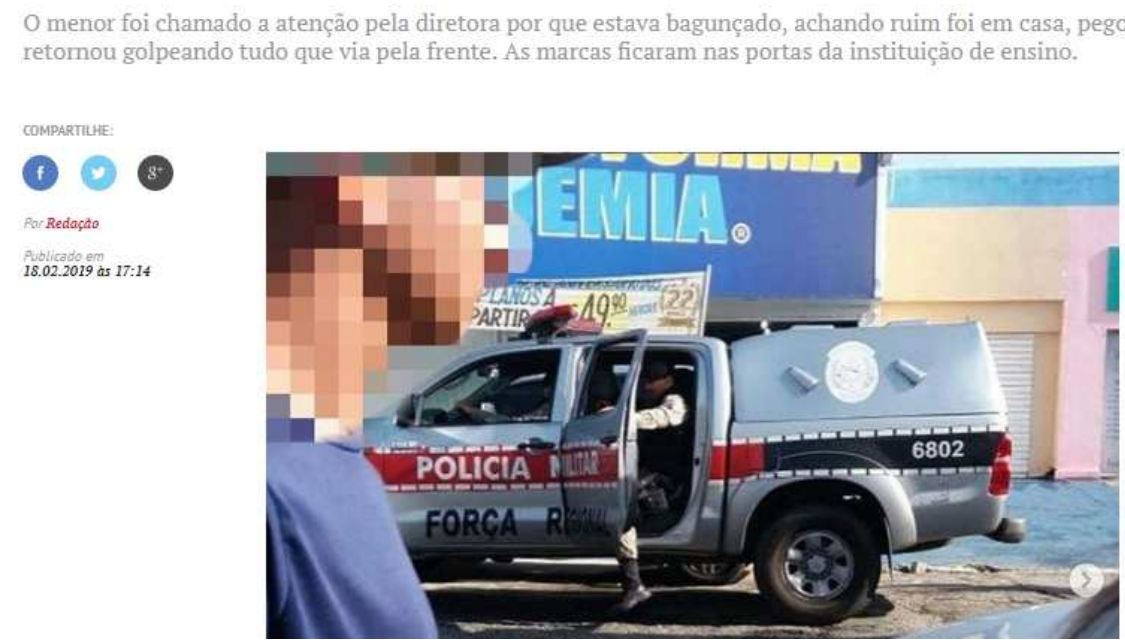

Fonte: https://www.clickpb.com.br/paraiba/aluno-tenta-matar-diretora-de-escola-no-jose-pinheiro-em-campinagrande.

Por fim, a última pergunta buscou investigar se os alunos já haviam sofrido com violência no lugar de suas residências. As respostas dos grupos foram as seguintes:

Apenas um discente fez um relato alusivo à violência que o seu pai sofreu em frente à sua residência, onde foi agredido fisicamente por vizinhos sob efeito de álcool e Grupo 1: entorpecentes. Mesmo não sofrendo com a violência, dois discentes relataram métodos de prevenção adotados em suas casas, como o aumento da altura do muro, instalação de cerca elétrica, grampos no muro e mais cadeados nos portões.

Nenhum dos discentes relatou sofrer com violência, porém um deles descreveu que Grupo 2: $\quad$ grampos foram inseridos no muro da sua casa como forma de prevenção de furtos e assaltos.

Após os grupos focais, foi realizada com os participantes a última oficina de mapas mentais, objetivando verificar se houve ampliação da percepção socioespacial após o desenvolvimento das estratégias. Os nove alunos dos grupos focais compuseram a amostragem. As figuras 5 e 6 apresentam a nova remessa de mapas produzidos na segunda oficina e são dos mesmos autores que compuseram a primeira oficina de mapas mentais. 
Figura 5: Segunda rodada de produção de Mapas Mentais: percurso casa-escola I.

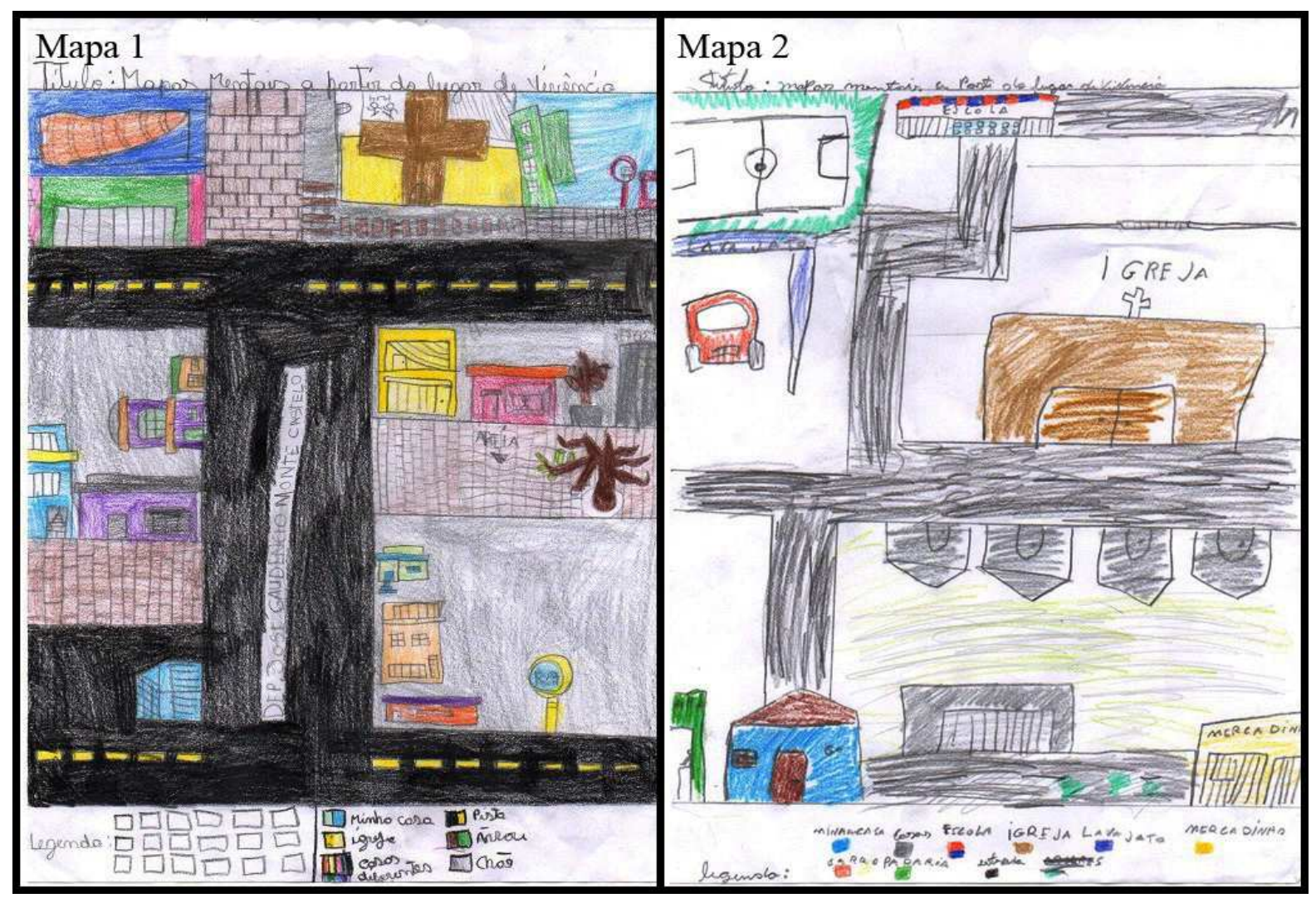




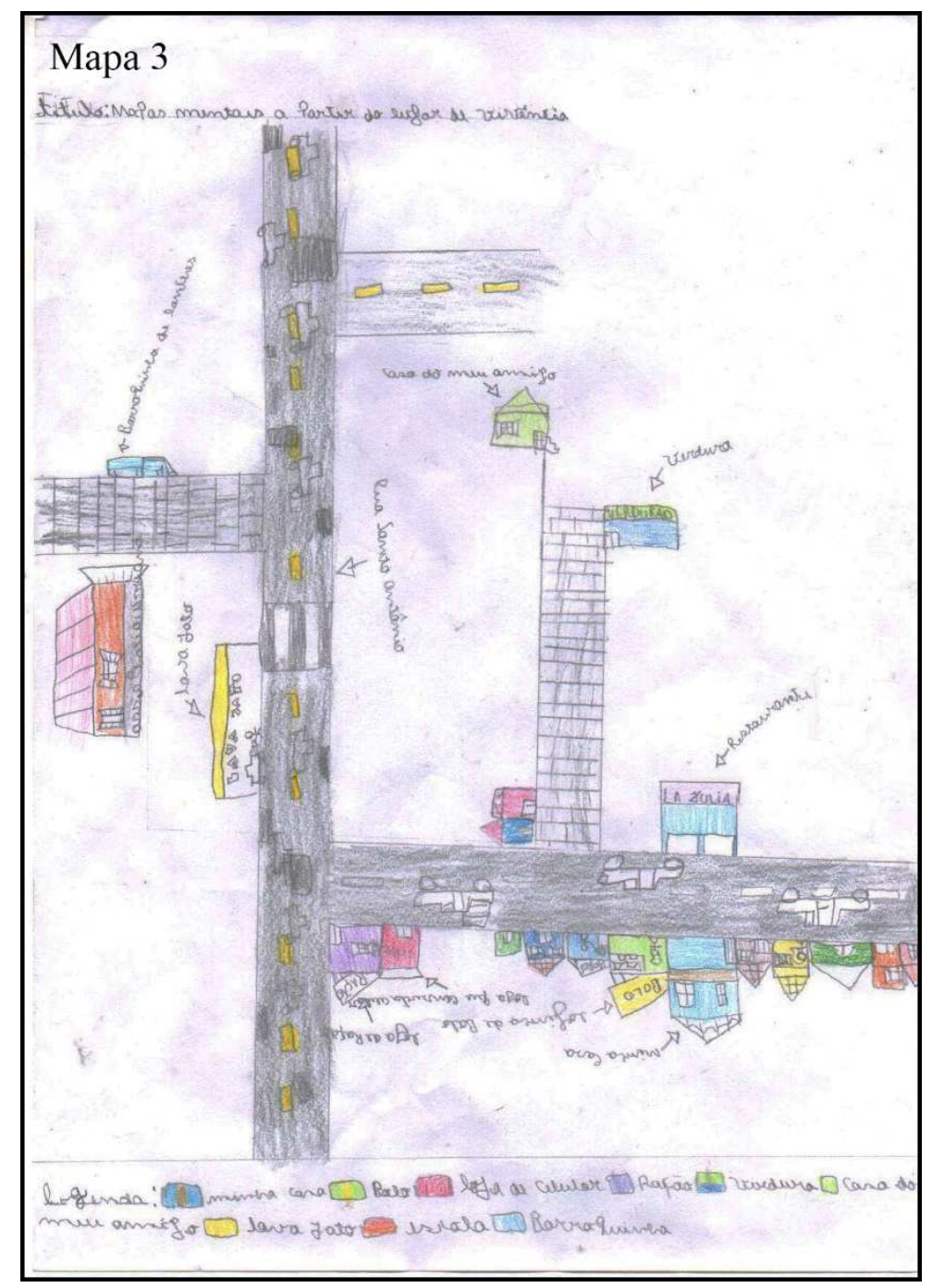

Fonte: Aluno 1, Aluno 2 e Aluno 3 (2019).

Em cada um dos mapas observou-se o maior detalhamento dos espaços representados pelos discentes, o que leva a identificar que houve ampliação da percepção dos elementos do espaço geográfico, e ainda sobre a percepção do lugar, destaca-se a ilustração das vias, corroborando com Spironello (2018), que apresenta as representações de vias como a demonstração do olhar do indivíduo sobre a cidade e sua noção de localização espacial, como apresenta o mapa 1, o autor identificou com precisão as vias asfaltadas e as pavimentadas, o mesmo ocorreu no mapa 3. 
Figura 6: Segunda rodada de produção de Mapas Mentais: percurso casa-escola II.

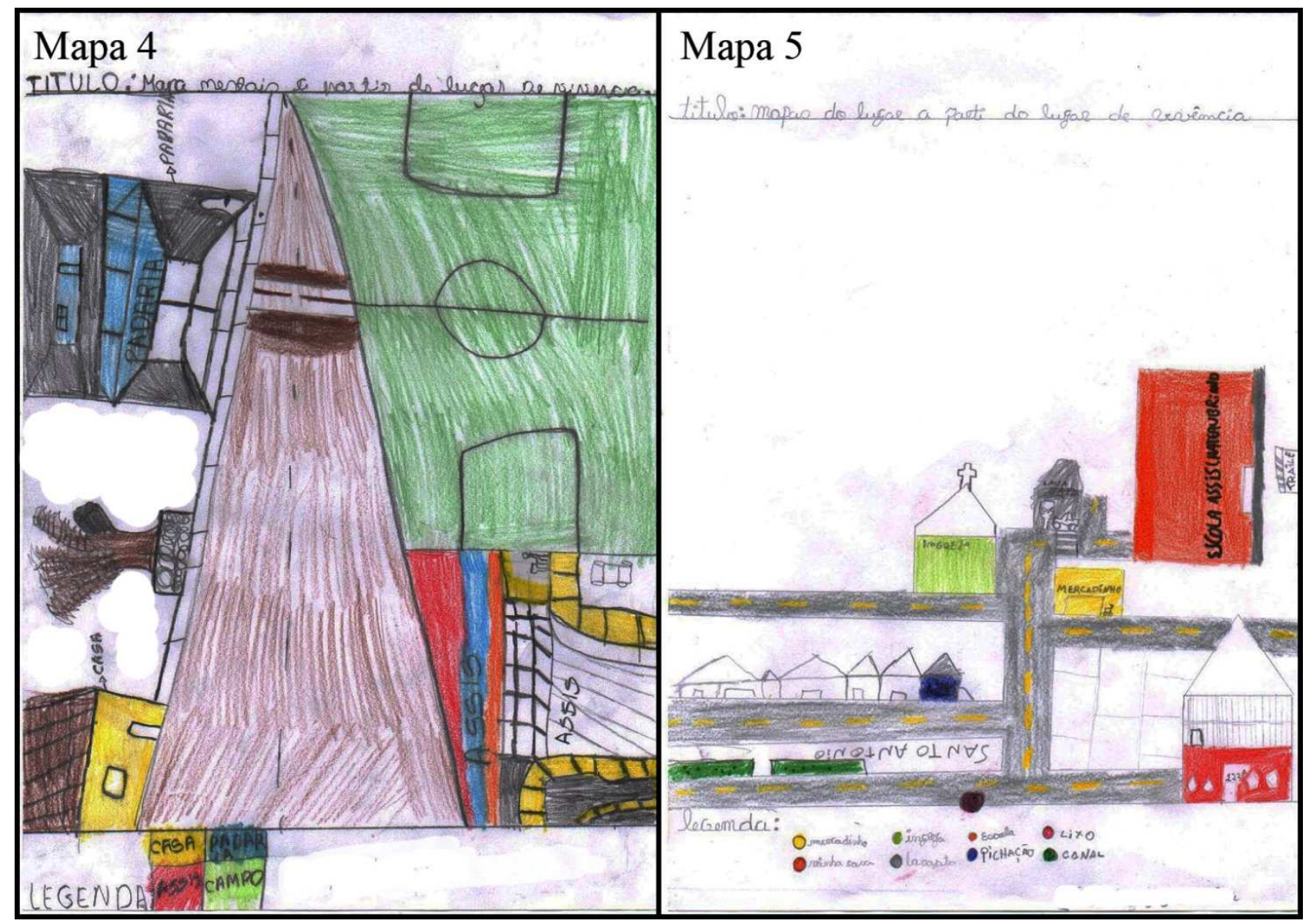

Fonte: Aluno 4 e Aluno 5 (2019).

O mapa 4, em comparação com a representação feita pelo mesmo autor na primeira rodada, apresentou maior detalhamento dos elementos, o autor representou o conhecido Pé do Tambor. Para muitos moradores do bairro, o espaço nas imediações da árvore é considerado um lugar, onde se reúnem cotidianamente construindo, além de relações de pertencimento, relações sociais. Sobre essas relações, Souza (2016) apresenta o lugar como espaço social, assim, todo lugar é um espaço social, porém nem todo espaço social é um lugar. Tendo o conhecimento que o lugar social é o espaço de interação da sociedade. E lugar se caracteriza por ser um espaço que carrega o significado do espaço de vivência.

Dando continuidade, o aluno representou cuidadosamente com perspectiva a padaria, na cor azul, o campo de futebol, espaço de lazer para a juventude das redondezas. Por fim, a 
escola Assis Chateaubriand, que foi fielmente representada, o aluno se deteve aos detalhes da estrutura e, na hora de colorir, procurou reproduzir as cores originais.

A partir dos mapas mentais colacionados ao texto, verifica-se que os alunos não enfatizaram nas suas representações a questão da violência, possivelmente em decorrência do fato de não se sentirem diretamente afetados por esse fenômeno, já que quando se reportaram ao ambiente escolar, enfatizaram o bullying e as pixações como formas de manifestação da violência presente nesse espaço.

\section{CONCLUSÕES}

O desenvolvimento do projeto na Escola Cidadã Integral Estadual de Ensino Fundamental e Médio Assis Chateaubriand, possibilitou aos alunos o aprendizado, compreensão e identificação de elementos através da leitura espacial, compreendendo a dinâmica e os aspectos socioespaciais e socioambientais que constituem os seus respectivos lugares cotidianos na Zona Leste da cidade.

As estratégias utilizadas para trabalhar com a turma se articularam ao conteúdo programático da sequência didática do $6^{\circ}$ ano, com enfoque na categoria geográfica lugar, e buscou a aproximação do conteúdo do livro com a realidade dos alunos. Os principais objetivos foram alcançados através da produção de mapas mentais, nesse momento os estudantes se tornaram construtores do conhecimento a partir dos entendimentos obtidos com as intervenções na representação individual de seus mapas.

O principal problema socioespacial que a pesquisa abordou foi a violência, devido a Zona Leste ser caracterizada como uma região violenta. Durante o desenvolvimento do projeto, percebeu-se que os estudantes não vivenciam essa violência urbana, pelo contrário, mais da metade deles se sentem seguros no seu lugar, esse fato se dá principalmente pela organização dos traficantes que protegem os moradores dos lugares vitimizados. Entretanto, mesmo os alunos não se percebendo como vítimas de violência urbana, essa questão foi debatida, nas modalidades violência urbana e psicológica, tanto no espaço de vivência como no ambiente escolar. Com a discussão sobre as principais formas de manifestação da violência, trabalhou-se com os alunos a identificação e combate de alguns desses hábitos que, infelizmente, se mostraram presentes em ambos os espaços. 
Foi de fundamental importância o projeto ter sido desenvolvido na escola, permitindo ao pesquisador assumir o papel de docente, desenvolvendo habilidades e competências de sua futura profissão, sendo uma experiência valorosa para sua formação. A universidade também cumpre um papel social, pois além de formar futuros profissionais, estendeu a sua atuação de forma mais objetiva, para o ambiente da educação básica que, nesse caso, foi o principal campo de pesquisa.

\section{REFERÊNCIAS}

ALEGRE, M. Geografia, cartografia - reflexões. Bol. Geogr., v. 1, n. 1, p. 1-6. 1983.

ALMEIDA, R. D.; PASSINI, E. Geografia: ensino e representação. São Paulo: Contexto, 1989.

BARROS, M. Das 50 cidades mais perigosas do mundo, um terço fica no Brasil. Saiba quais são e qual é a mais violenta do país. Revista Veja. Atualizado em 31 de julho de 2020.

Disponível em: https://veja.abril.com.br/blog/cidades-sem-fronteiras/das-50-cidades-maisperigosas-do-mundo-um-terco-fica-no-brasil-saiba-quais-sao-e-qual-e-a-mais-violenta-dopais/. Acesso em: 13 jun. 2021.

COLTRO, A. A Fenomenologia: um enfoque metodológico para além da modernidade. Caderno de Pesquisa em Administração, São Paulo, v. 1, nº 11, 2000.

COSTA, G. C. Sentidos da milícia: entre a lei e o crime. Campinas: Unicamp, 2014.

FERREIRA, I. C. B.; PENNA, N. A. Território da violência: um olhar geográfico sobre a violência urbana. São Paulo, GEOUSP: Espaço e Tempo, n. 18, p. 155-168, 2005.

FERREIRA, K. F. C. A percepção do lugar de vivência expressa através dos mapas mentais: experiência a partir do subprojeto geografia- PIBID/CAPES/UEPB. 2014. 38 f. Trabalho de Conclusão de Curso (Graduação em Geografia) - Universidade Estadual da Paraíba, Campina Grande, 2014.

GODOY, A. S. Introdução à pesquisa qualitativa e suas possibilidades. RAE, São Paulo, v. 35, n. 2, p. 57-63, mar./abr. 1995.

HOLZER, W. O Lugar na geografia humanista. Revista Território, Rio de Janeiro, ano IV, n. 7, p. 67-78, jul. /dez. 1999. 
HOLZER, W. A Geografia Humanista uma Revisão. Espaço e Cultura. n. 3, jan. 1997. Disponível em: http://www.epublicacoes.uerj.br/index.php/espacoecultura/article/viewFile /6707/4783. Acesso em: 24 abr. 2019.

HORIKAWA, A. Y. Pesquisa Colaborativa: Uma construção compartilhada de instrumentos. Revista Intercâmbio, São Paulo: LAEL/PUC-SP, v. XVIII, p. 22-42, 2008.

LOPES, A. R. C. O lugar e os mapas mentais na Geografia Escolar. Revista Brasileira de Educação em Geografia, Campinas, v. 8, n.16, p. 391-410, jul./dez. 2018.

MARTINELLI, M. Gráficos e mapas: construa-os você mesmo. 1. ed. São Paulo: Editora Moderna, 1998. v. 1.

MARTINELLI, M. Mapas da Geografia e Cartografia Temática. 4 ed. rev. e atual. 2. ed. São Paulo -SP: Contexto, 2008. v. 1.

MORAIS, N. R.; MELO, J. A. B. Discutindo as categorias Geográficas no Ensino Médio a partir de novas metodologias didáticas. Revista de Geografia (UFPE), Recife, v. 32, n. 1, p. 167-185, 2015.

MOREIRA, D. A. O método fenomenológico na pesquisa. Pioneira Thomson, São Paulo, 2002.

OLIVEIRA, L. Estudo metodológico e cognitivo do mapa. São Paulo, SP: Série de Teses e Monografias, IG - USP, 1978.

PENHA, J. M.; MELO, J. A. B. Ensino de Geografia: Categorias de análise e percepção do espaço de vivência pelos alunos. Revista de Geografia (Recife), Recife, v. 2, n. 2, p. 1-18, 2019.

PEREIRA, A. C. S.; WILLIAMS, L. C. A. Reflexões sobre o conceito de violência escolar e a busca por uma definição abrangente. Temas em Psicologia, São Carlos, 2010, v. 18, n. 1.

PEREIRA, H. S. S.; ROSALES, A. F. A.; MELO, J. A. B. O Lugar de Vivência Interpretado por Mapas Mentais. XIX Encontro Nacional de Geógrafos, Anais..., João Pessoa, 2018.

RICHTER, D. O mapa mental no ensino de geografia: concepções e propostas para o trabalho docente. São Paulo: Cultura Acadêmica, 2011.

RODRIGUES, A. M. Geografia e violência urbana. In: PONTUSCHKA, N. N.; OLIVEIRA, A. U. Geografia em perspectiva: ensino e pesquisa. São Paulo: Contexto, 2002. 
SANT'ANNA, M. J. G. O papel do território na configuração das oportunidades educativas: efeito escola e efeito vizinhança. In: CARNEIRO, S. S.; SANT'ANNA, M. J. G. (orgs.). Cidade: olhares e trajetórias. Rio de Janeiro, Garamond, 2009.

SANTOS, A. D. Vila Olímpica Plínio Lemos em Campina Grande, PB: transformações socioespaciais de um espaço público. 2011. 78. Trabalho de Conclusão de Curso (Graduação em Geografia) - Universidade Estadual da Paraíba, Campina Grande, 2011.

SANTOS, M. O país distorcido: o Brasil, a globalização e a cidadania. In: RIBEIRO, W. C.; GONÇALVES, C. W. P. (Orgs.). São Paulo: Publifolha, 2002.

SIMIELLI, M. E. R. Cartografia no Ensino Fundamental e Médio. In: CARLOS, A. F. A. (Org.). A Geografia na sala de aula. 1ª ed. São Paulo: Contexto, 1999, v. 1, p. 92-108.

SPIRONELLO, R. L. A cartografia escolar e a elaboração de mapas mentais na educação de jovens e adultos: contribuições para o processo de ensino e aprendizagem. Boletim Paulista de Geografia, v. 99, p. 213-230, 2018.

SOUZA, M. L. Os Conceitos Fundamentais da Pesquisa Sócio-espacial. 3. ed. Rio de Janeiro: Bertrand Brasil 2016.

VIERO, V. C; BARBOSA FILHO, L. C. Praças Públicas: Origem, conceitos e funções. In: Jornada de Pesquisa e Extensão. 2009, Santa Maria.

TUAN, Y. F. Espaço e lugar: a perspectiva da experiência. Tradução de Lívia Oliveira. São Paulo/Rio de Janeiro: DIFEL, 1983. 